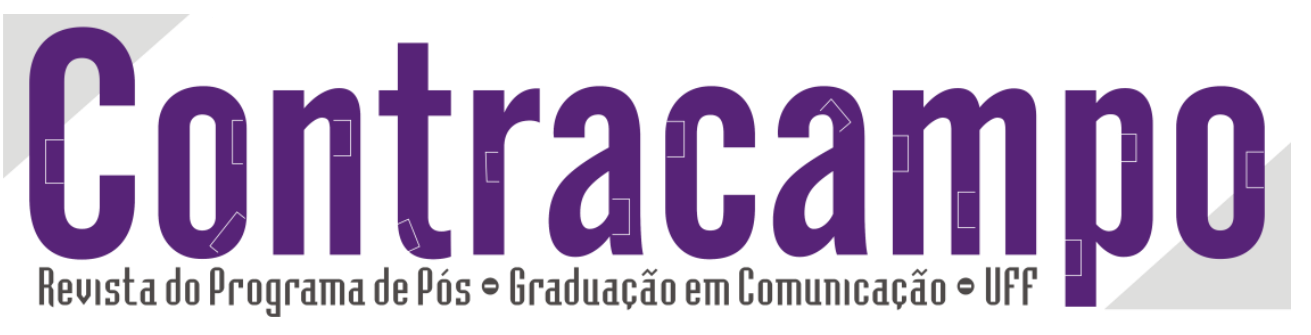

\title{
Consumo musical nas culturas juvenis: Cosplay, mundo pop e memória
}

\section{Music consumption of youth cultures: Cosplay, pop world and memory}

\section{Mônica Rebecca Ferrari Nunes nunes.aureli@uol.com.br}

Pesquisadora e Docente do Programa de Pós-Graduação Stricto Sensu em Comunicação e Práticas de Consumo, PPGCOMESPM, SP. Doutora em Comunicação e Semiótica pela Pontifícia Universidade Católica de São Paulo.

${ }^{1}$ Este artigo é uma versão revista e parcialmente ampliada do texto apresentado no $X$ Congreso de la Asociación Internacional para el Estudio de la Música Popular Rama Latinoamericana. 18 a 22 de abril de 2012. Córdoba, Argentina.

Ao citar este artigo, utilize a seguinte referência bibliográfica

NUNES, Mônica Rebecca Ferrari. Consumo musical nas culturas juvenis: cosplay, mundo pop e memória.In: Revista Contracampo, $\mathrm{n}^{\mathrm{o}}$ 25, dez. de 2012. Niterói: Contracampo, 2012. Pags: 80-96.

Enviado em: 23 de set. de 2012 Aceito em: 20 de dez. de 2012

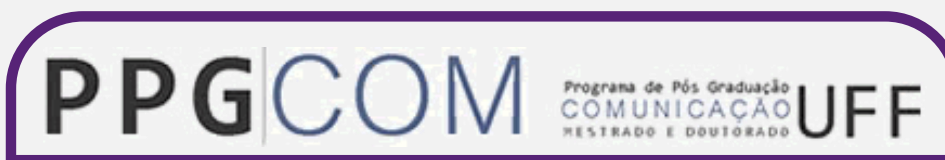

\section{Edição 25/2012}

Ensaio temático "Mídia e Medo"

Contracampo

e-ISSN 2238-2577

Niterói (RJ), n‥ 25, dez/2012.

www.uff.br/contracampo

A Revista Contracampo é uma revista eletrônica do Programa de PósGraduação em Comunicação da Universidade Federal Fluminense e tem como objetivo contribuir para a reflexão crítica em torno do campo midiático, atuando como espaço de circulação da pesquisa e do pensamento acadêmico. 


\section{Resumo}

Este trabalho integra o projeto de pesquisa Comunicação, consumo e memória: cosplay e culturas juvenis. Fundamentado nos conceitos propostos pela Escola de Tártu-Moscou sobre cultura e memória e nos estudos contemporâneos sobre comunicação, cultura e consumo, este paper traz os resultados parciais sobre a subcultura cosplay com base no evento Anime Party 2012 e Anime Dreams 2012. Aqui, as bandas formadas pelos cosplayers e os repertórios musicais consumidos são textos culturais responsáveis por processos de construção de memórias e de vínculos essenciais à permanência desta cena juvenil. Investiga-se a paisagem sonora da cena cosplay, pois a música, como sistema sígnico, tem participação decisiva nesta semiosfera que reúne igualmente concursos de "animekês" e games musicais.

Palavras-Chave: Consumo musical, cosplay, culturas juvenis.

\section{Abstract}

This paper is part of a broader research named Comunicação, consumo e memória: Cosplay e culturas juvenis (free translation: Communication, consumption and memory: Cosplay and youth cultures). These are cosplay subculture findings from an initial investigation conducted at the Anime Party 2012 and Anime Dreams 2012 events and follow concepts proposed by the Tartu-Moscow School on culture and memory, as well as contemporaneous studies in communication, culture and consumption. Cosplayers' bands and their music repertory form cultural texts, forge the processes of memory construction and bonds, essential for maintaining the youth scene. Cosplay soundscape is this study's target since music, as a semiotic system, plays a decisive role in this semiosphere, which gathers animeke contests and music games.

Key-Words: Music consumption, cosplay, youth cultures. 
$\mathrm{O}$ cosplay, contração de costume play, chega ao Japão a partir de 1980, tornandose uma prática expressiva entre os jovens urbanos. Os cosplayers se vestem e atuam conforme as personagens de mangás - histórias em quadrinhos impressas em papel jornal, em preto e branco, que podem ser, posteriormente, animadas para vídeos (OVAs - Original Video Animation) e para a tevê sob a denominação de animês. Tokusatsus - filmes de efeitos especiais cujos protagonistas são monstros e/ou superheróis - servem também como inspiração para os cosplayers. Naquele mesmo decênio, o Japão assistiu ao fortalecimento das indústrias dos mangás e animês e ao processo de exportação destes produtos culturais para os EUA, Europa e América Latina (NAGADO, 2005). Os eventos de cosplay chegaram ao Brasil ao final dos anos de 1990 (AMARAL E DUARTE, 2008; COELHO JR. E SILVA, 2007) e, atualmente, seus participantes têm em múltiplas personagens midiáticas fontes para montagem de seus trajes: das personagens de animês aos ícones da música pop ou do universo editorial.

Hoje os encontros congregam uma série de atividades, além dos concursos de cosplays, tais como os campeonatos de ilustração, de games, de cards, de espadas medievais, shows, apresentação de bandas, animekês (karaokês compostos por trilhas sonoras de animês), além da comercialização de roupas, acessórios, mochilas, camisetas, bottons, em sua maioria, associados a narrativas midiáticas, sejam geradas por mangás, animês, tokusatsus, filmes, games ou livros.

No presente artigo, analiso os eventos Anime Dreams e Anime Party $2012^{1} \mathrm{e}$ denomino este conjunto de práticas como cena cosplay, ampliando o conceito de cena estudado por Will Straw (2004), inicialmente voltado apenas à música. Aqui, a cena musical insere-se na cena cosplay, por seu turno, tomada como prática de sociabilidade reunindo ambientes comunicacionais diversos, atores sociais, além dos processos de produção, circulação, consumo e memória articulados em uma rede de produção de sentido.

\footnotetext{
${ }^{1}$ Anime Dreams 2012 é um dos eventos que congrega a cena cosplay. Realizei pesquisa de campo entre os dias 13, 14 e 15 de janeiro de 2012. Porém, este artigo refere-se, majoritariamente, às pesquisas que realizei durante outro evento: Anime Party efetuado entre 17 e 18 de março de 2012. Mas, alguns depoimentos coletados durante o Anime Dreams foram agregados aqui graças às referências ao papel desempenhado pela música nos animês e nos festivais, objeto de investigação desta etapa da pesquisa.
} 
A pesquisa reconhece esta cena também como semiosfera (LOTMAN, 1996): espaço semiótico necessário para o funcionamento da cultura; composta por variados sistemas de signos que asseguram a produção da semiose - em um continuum. Espaço fechado, de caráter abstrato, torna a vida de relação possível, e, como sustenta o semioticista Iuri Lotman (1996: 35):

a semiosfera do mundo contemporâneo, alargando-se no espaço ao longo dos séculos, inclui dentro de si, tanto os sinais dos satélites como os versos dos poetas e os gritos dos animais. A interconexão de todos os elementos do espaço semiótico não é uma metáfora, mas uma realidade. (LOTMAN, 1996: 35)

Analogamente à biosfera, a semiosfera é uma esfera viva, dinâmica, pois os sistemas de signos, imersos em seu interior, comunicam-se dialogicamente e de modo interdependente. O dinamismo se dá, também, graças ao fato de que a significação gerada por estes sistemas é um processo inacabado. A cultura será sempre processual, jamais um resultado absoluto.

As teses dos pesquisadores da Escola de Tártu-Moscou apontam o texto como a unidade de base da cultura, de alto grau de complexidade. A noção de texto se expande, liberta-se da concepção exclusivamente linguística, de um enunciado, para abarcar todo e qualquer portador de sentido. No decorrer dos estudos em semiótica da cultura, foi importante a observação de textos como o ritual, a cerimônia, a representação dramática, que levaram à combinação de tipos essencialmente diferentes de semiosis, cujo resultado, como menciona Lotman (1996: 79), conduziu "ao surgimento de complexos problemas de recodificação, equivalências, trocas de pontos de vista e combinações de diferentes vozes em um único todo textual".

O estudo dos textos artísticos demonstrou que o texto cultural possui muitos estratos, é semioticamente heterogêneo, capaz de intrincadas relações tanto com o contexto cultural circundante quanto com o público leitor. Desse modo, ele deixa de ser uma mensagem elementar dirigida do destinador a um destinatário e passa a ser avaliado tendo em vista certas propriedades, tais como a capacidade de condensar informação, gerar sentido, adquirir memória. O texto é "logos que cresce por si mesmo" (LOTMAN, 1996: 80). Tem a propriedade de um dispositivo intelectual: transmite 
informação depositada nele, de fora dele, mas também transforma mensagens e produz novas mensagens.

Em consequência, este paper procura revelar certos aspectos da cena cosplay avaliada como semiosfera, formada por inúmeros textos. Um dos textos analisados é a linguagem musical, seja na forma dos concursos de animekês, onde "animekeiros", como são chamados, cantam as trilhas de seus vídeos preferidos, seja na formação das bandas de animês, $J$ pop, $K$ pop ou enka, gêneros japoneses e coreanos explicitados adiante.

Os animês, animekês, games e bandas presentes, nos festivais, são considerados os meios de transmissão privilegiados para a construção da paisagem sonora desta cena - trazem também os repertórios consumidos por estes jovens e demonstram modos de seleção de sucessos que diretamente contribuem para a escolha e montagem do cosplay.

Vale explicitar que a denominação paisagem sonora deriva dos trabalhos do musicólogo Murray Schafer (2001). O compositor canadense entende que a primeira paisagem sonora, isto é, o ambiente acústico primordial foi gerado pelas águas. Do oceano ancestral aos sons do útero materno, o autor discorre, em sua cartografia sonora, sobre geografias e climas, configurações de vilas, cidades, paisagens da natureza e paisagens artificiais reconhecendo os ambientes acústicos, diagnosticando situações de comunicação produzidas por meio dos sons, quer seja em sua dimensão estética, simbólica, econômica ou política.

De toda maneira, interessa perceber a importância da paisagem sonora na elaboração da cena cosplay e apontar seus traços significantes em confluência com os conceitos da semiótica da cultura e da mídia e sua interface com as teorias do consumo. Compreendendo consumo seguindo

a concepção de uma 'imagética do consumo' - terminologia que prevê uma interpretação menos focada em produtos ou serviços, em si, mas que considera a inserção do consumo em toda uma cena ou rede midiática, rizomática e dinâmica. (ROCHA, 2008: 123)

Destarte, a paisagem sonora-imagética reverberante na prática cosplay destaca a musicalidade da voz, em toda sua extensão significante, temáticas e sons do mundo pop 
conectados à construção de processos de identificação, memórias e vínculos essenciais à permanência desta cena juvenil na cultura de consumo.

Conforme ensina Mike Featherstone (1995: 121), "usar a expressão cultura de consumo significa enfatizar que o mundo das mercadorias e seus princípios de estruturação são centrais para a compreensão da sociedade contemporânea". O autor ainda insiste sobre a necessidade de atentar à "simbolização e o uso de bens materiais como 'comunicadores', não apenas como utilidades". Tarefa proposta para a observação do consumo musical nas culturas juvenis com base na cena cosplay.

\section{Cena musical cosplay, meios de transmissão e consumo}

Graças ao seu caráter sistêmico, a semiosfera atua como um organismo vivo e o funcionamento dos diversos sistemas de signos e de textos que a integram será forçosamente dialógico, submersos em um continuum semiótico, de linguagem igualmente um continuum cultural. Desse modo, a música como texto de cultura poderá dialogar ou gerar interferências, provocar tensões ou acordos com outros textos que compõem a cena, como a moda, as narrativas midiáticas (mangás, animês, tokusatus, games) e seus personagens e/ou as histórias de vida dos próprios cosplayers, narrativizadas e textualizadas.

Kakao, 19 anos, cosplayer, faz fairy kei, estilo de moda urbana japonesa, seguindo a tendência de tons pastéis, delicados, infantis"2: "uma coisa Ursinhos Carinhosos, Meu Querido Pônei ${ }^{3}$, mais contos de fadas, mas que pega uma vibe anos 80" (Kakao). De peruca rosa, tapa orelhas de pelúcia rosa e azul, vestido curto de babadinhos, resume as relações entre a música e a moda na cena cosplay: "querendo ou não, caminham junto ${ }^{4}$ porque é cultura japonesa [...], eu gosto de $K$ pop”, emenda.

\footnotetext{
2 Disponível em <http://www.harajukulovers.com.br/index.php/2009/12/03/estilo-fairy-kei>. Último acesso em 13 de fevereiro de 2012. Considero o fairy kei também um cosplay. Kakao frequenta os eventos desde 1999.

${ }^{3}$ Meu Querido Pônei foi concebido como brinquedo pela empresa Hasbro e, em 1984, ganhou versão para televisão e posteriormente para o cinema. Ainda na década de 80, esta mesma estratégia foi utilizada para transformar a coleção de pelúcia, Ursinhos carinhosos, em desenho de animação (Walt Disney Pictures). Disponível em <http://www.infantv.com.br/poney.htm.>. Acesso em 11 de fevereiro de 2012.

${ }^{4}$ As transcrições destas entrevistas obedeceram à linguagem oral dos depoentes.
} 
O J Pop e K Pop, estilos de música pop japonesa e coreana, figuram na lista dos preferidos dos cosplayers e das bandas que por lá transitam, assim como os anime songs - segmento do mercado fonográfico nipônico relacionado às trilhas sonoras dos animês, games, tokusatus e daquelas especialmente criadas para personagens de mangás. Nagado (2005: 54) sustenta que "diversos mangás já inspiraram CDs com diálogos de histórias e músicas compostas para servirem de apoio aos quadrinhos".

Kakao explica as diferenças entre o $J$ e $K$ pop: “[...] a diferença na real mesmo é só a letra, é só a língua". A jovem consegue rapidamente criar o mapa da transmidialidade e demonstrar que os processos de identificação com um país se valem de marcas sígnicas, desde os sistemas sonoros - perpassando territórios icônicos da musicalidade da voz, suporte da língua pátria - até a música como um sistema simbólico, isto é, com suas leis de composição, convergindo para os sistemas audiovisuais e seus textos culturais, como os mangás e animês, com os quais estabeleceu contato, como aponta seu relato:

eu não sei nada em coreano, mas japonês, uma coisa ou outra eu entendo, que é a convivência de muitos anos. Aí você lê mangá, você assiste animê, você assiste filme, você assiste mil coisas e você ouve a música, aí você vai pegando uma palavra ou outra. [...] você já vai ficando mais íntima do país. Eu imagino que se eu fosse pro Japão, eu ia me virar super bem. É que eu conheço tudo que tem lá, tudo!

Kakao não descende de orientais, tampouco Kimi, 27 anos, cosplayer e "animekeira", que usa esse "codinome", pois não gosta de seu nome próprio. Com 10 anos, ela comprava mangás, e a mãe, percebendo seu interesse na leitura, matriculou a menina em uma escola. Fez curso avançado em japonês graças aos mangás e animês. Hoje é professora de inglês, mestranda em Linguística Aplicada na Pontifícia Universidade Católica de São Paulo. Na entrevista, pergunto de que modo transfere sua experiência de "animekeira" e de cosplayer para sua vida fora dos eventos. Ao responder, revela também seu desejo: 
eu gosto muito de idiomas, dou aula de inglês e tento transferir pros meus alunos a importância de se falar uma outra língua [...] um idioma não é só um idioma, ele é cultura [...] se você aprende japonês, aprende a cultura japonesa [...] eu tô me esforçando pra pegar uma turma de japonês, seria a minha primeira, mas é difícil passar credibilidade, ainda se tem a imagem de que um professor de japonês tem que ser japonês [...].

Por que canta animês? As imagens e sons da infância parecem fulcrais para esta escolha singular: "gostava dos animês desde pequena [...] as letras têm sempre uma mensagem de amizade, de superação, de não abrir mão dos seus sonhos”.

Nos depoimentos da jovem, é possível observar a relação entre o texto e o contexto cultural do qual nos fala Lotman (1996: 81). Já que o contexto cultural é um fenômeno complexo e heterogêneo, "um mesmo texto pode entrar em diversas relações com as diversas estruturas dos distintos níveis do contexto". Assim, o mangá, como texto cultural, participa em variados níveis da experiência contextual de Kimi: aprender idiomas, gostar de cantar trilhas de animês.

Na cena cosplay, as transmissões midiáticas se materializam no trânsito literovoco-musical-têxtil de certos textos culturais, dos mangás, animês e games aos anime songs e outros gêneros pop ou rock, japonês ou coreano, à moda. Estas conexões contribuem simultaneamente para investimentos identitários, como as identidades étnicas marcadas no discurso de Kakao e Kimi - uma vez que o texto cultural pode também motivar produções de subjetividade - e, da mesma forma, desenham mapas de consumo em sua dimensão comunicativa, pois narrativas midiáticas, moda e sonoridades constroem imaginários pautados na superação, na amizade e "na revolução pela delicadeza", a exemplo dos valores defendidos por Akemi, jovem nissei que se monta como Lolita, um dos gêneros visuais da moda urbana japonesa.

Segundo a jovem, ser Lolita é ter babados nas saias e nos vestidos rodados, meia calça sempre, cabelos loiros, "arrumadíssimos", olhos emoldurados por longos cílios, rosto de boneca, sapatos de laços e fitas. Estilo nascido no bairro Harajuko, em Tóquio, pautado também por mercadorias lúdicas como a boneca Hello Kitty e outros

\footnotetext{
${ }^{5}$ Revolução kawaii, cujo significado em japonês, é fofo, mimo. A tônica da revolução é combater a violência pela beleza das flores, rendas e temas correlatos, conforme explica Akemi, jovem Lolita e vocalista da banda NouHaw.
} 
produtos extensivos à culinária, a exemplo dos cupcakes coloridos e decorados, "o bolinho das Lolitas", confirma Akemi. Reúnem-se em casas de chá no centro de São Paulo, vestem-se cobrindo todo o colo, em estilo vitoriano e rococó, conservando "eternamente o jeito menina associado à personagem de Nabokov", emenda a cosplayer explicando que a moda deve levar o bem às pessoas e, por isso, acredita na revolução kawaii.

A Lolita Akemi destaca a importância de se comportar gentilmente, porém esta maneira de ser não impede sua atuação como vocalista na banda NouHaw. Surgida em meados de 2010, em São Paulo, “com a intenção de fazer uma releitura da cultura pop japonesa no Brasil, através de composições e visual próprios, influenciados pela música e moda japonesa", conforme o site do grupo ${ }^{6}$, a banda se apresenta com anime songs, $\mathrm{J}$ pop e músicas próprias, nos festivais da Yamato ou em outras ocasiões.

De modo parecido às afirmações de Kimi sobre os motivos de gostar dos anime songs: as mensagens de superação. O site da banda NouHaw descreve as razões do nome do grupo: "NouHaw faz referência ao termo 'Know How' e foi escolhida por ser uma palavra bastante positiva e que remete aos esforços realizados em nossas conquistas". Akemi, trajando-se como Lolita, acompanha Takao, no violão e guitarra, Tschiiti Shibata, no baixo, e Akashi Miyata, na percussão e teclado. Os garotos fazem o "estilo rockeiro" cabeludo, roupas desleixadas, a princípio, contraditório à doçura prevista para o comportamento de uma Lolita.

Se os estudos sobre o consumo devem ser compreendidos como sistema de significação, superando necessidades simbólicas, funcionando como código a partir do qual nossas relações sociais e subjetivas se tramam (ROCHA E BARROS, 2008), podese afirmar que o consumo simbólico e material dos produtos midiáticos analisados não funciona apenas como convenção, mas atua, sobretudo, como código cultural. Para a teoria semiótica de Tártu-Moscou, os códigos culturais são complexas estruturas de armazenamento e processamento de informações. "Todos os códigos, do bio ao socius, são culturalizações [...] são formas convencionalizadas que situam o homem no ambiente. Os códigos traduzem as informações apreendidas pelo sensório ou perceptos" (MACHADO, 2003: 156).

\footnotetext{
${ }^{6}$ Disponível em< http://nouhaw.jimdo.com>. Último acesso em oito de abril de 2012.
} 
Torna-se viável a captura icônica de traços das personagens do bairro Harajuko, do mundo pop, do rock ou dos animês, e a tradução desta experiência sensória na prática Lolita, como vocalista de J Pop, tal qual a performance de Akemi, ou na prática cosplay, como faz Lucas, um "otaku ${ }^{7}$, crazy”, como diz de si. Negro, 19 anos, seleciona as personagens que gosta, para montar o cosplay, "pelo bordão [...], pela fala, pelo movimento", isto é, pela musicalidade da fala - tão importante quanto os movimentos das personagens que gozam de seu afeto. O jovem refere-se aos animês vistos na extinta tevê Manchete como responsáveis por sua identificação junto à cultura japonesa: “desde que eu me entendo como gente, eu acho que eu já tinha instinto pra ser otaku porque a primeira vez que eu fui na Liberdade $^{8}$ com meu pai, eu achava que eu realmente estava no Japão".

O consumo como código cultural é mediação sígnica - não só extensão do sensório-permite a criação de textos culturais. Com base nas práticas e depoimentos analisados, supõe-se que se consome, nas dimensões de produção e recepção, um Japão como texto cultural imaginado e imaginário. Um texto de muitos estratos. Heterogêneo em sua articulação de voz, sons, complexos audiovisuais, texturas (no sentido da linguagem da moda) e desejos expressos nas identidades que alguns cosplayers e animekeiros reivindicam: fairy kei, Lolita, otaku. Conhecer o Japão sem nunca ter ido lá, como Kakao ou Kimi, é também pela via da memória, sempre inventada, experimentar ser japonês. Processos realizados na tensão entre um desejo essencialista, ser isto ou aquilo, e a experiência da montagem e desmontagem de possibilidades identitárias.

\section{Consumo musical e memória sonora}

\footnotetext{
${ }^{7}$ Ao estudar a origem do cosplay no Japão, Éthienne Barral (apud AMARAL E DUARTE, 2008), mostra que o cosplayer pode ser associado ao otaku - jovem imerso na parafernália tecnológica, isolado de sua parentela tradicional, com dificuldade de se relacionar com os outros. Para o autor, muitos destes garotos se inspiram em personagens dos mangás e animes e, assim, o jovem otaku "se apropria de uma determinada materialidade tecnológica e a transforma de acordo com seu próprio gosto e identidade, ampliando tanto o repertório de artefatos culturais como ressignificando as práticas de consumo" (BARRAL apud AMARAL E DUARTE, 2008: 278). Há diferenças entre os significados denotados ao otaku no Japão e no Brasil. Estas particularidades escapam aos interesses deste artigo.

${ }^{8}$ A Liberdade é um bairro paulista com forte concentração de imigrantes japoneses e mantém inúmeros traços da cultura oriental: de signos arquitetônicos e urbanísticos a realizações de celebrações e festas tradicionais do Japão.
} 
A cena musical dos encontros contempla também inúmeras bandas compostas por fãs da cultura pop japonesa que fazem do palco o lugar em que a animação se une à performance, no sentido atribuído por Zumthor (1997): transmissão da voz poética valendo-se do corpo vivo - para testemunhar um modo de compartilhamento típico das culturas jovens atuais, que não exige laços perenes, conforme o argumento de Ferreira (2008) de que as microculturas juvenis não se configuram um "nós associativo", graças à fragmentação intrincada e reticular, mas sim, "nós sociativos conexos".

Nestas condições, as bandas podem ser entendidas como práticas expressivas das culturas juvenis urbanas em diálogo com novas plataformas de informação e entretenimento, acatando as observações de Herschmann (2011: 110): "parte-se do pressuposto de que o crescimento do consumo de games, especialmente o dos videogames musicais [...] vem desempenhando um papel pedagógico, incentivando e levando muitos jovens a se interessarem pela prática dos instrumentos musicais".

Particularmente, a hipótese aventada pelo autor reverbera na fala de Camila, 20 anos, vocalista da Banda Iikagem, ${ }^{9}$ ao narrar a formação do grupo, em 2008, em São Bernardo: "nós todos éramos amigos e a gente jogava um joguinho que interessava todo mundo, um jogo de dança [...] E a gente começou a falar de banda e tal e tal, porque tal música [do game] era legal e aí surgiu o interesse". Camila narra as dificuldades iniciais em "tirar" as músicas, "porque não tinha a tablatura [...], como a gente era novo, a gente não tinha uma noção maior".

Tocavam inicialmente rock coreano, e, com o tempo e a frequência nos eventos de animês, que "já faziam parte da vida do grupo", como revela a jovem, resolveram ocupar o nicho no mercado de bandas independentes no segmento animê, ainda que procurem um caminho musical próprio: “a gente quer se destacar pela diferença musical, entendeu? Por a gente tocar, fazer solos em cima da música e jogar um blues, um jazz, um forró" (Raoni, baixista). A cena musical cosplay acolhe outros estilos. Lucas, o guitarrista da Iikagem, avalia: "na verdade, é muito relativo né, [...] às vezes a gente fala: não, a gente só toca música de anime, só que dentro das músicas de anime tem um pouco de $J$ Rock e tudo mais [...]".

Seguindo as constatações de Martín-Barbero (apud BORELLI E FREIRE, 2008), milhões de jovens se juntam sem falar, só para compartilhar a música e para estar

\footnotetext{
${ }^{9}$ A banda Iikagem, em japonês, randômico - é formada por Camila, vocal, Raoni, baixista, e Lucas, na guitarra. Jovens de São Bernardo do Campo, SP.
} 
juntos através da comunicação corporal que ela gera. A música, como texto cultural, condensa e gera memória. Tal qual o enka, forma de balada japonesa em tom choroso nas partes vocais; primeiro estilo a unir melodias japonesas com outras harmonias: rockabilly, bluegrass, sonoridades havaianas e latinas. Conforme Braga (2009: 114), "graças a sua capacidade para absorver um grande número das mais diversas influências, [o enka] tem se mantido um estilo popular ao longo dos tempos". Hoje este gênero foi absorvido por muitas bandas independentes, como a Gaijin, presente nos eventos de animês e em outros voltados à colônia japonesa, e executa o gênero enka com flautas de bambu e atrai públicos mais saudosos, como revela Akira Barros (2011).

A nostalgia não favorece apenas ao consumo como código cultural que classifica em categorias estanques o mundo de jovens e o de velhos. No caso dos festivais de cosplay, a experiência da memória sonora coloca em andamento produções de vínculos e sociabilidades, diluindo faixas etárias. Como sublinha Camila, ao responder sobre os motivos que levaram a banda a tocar apenas animês: "tem a ver com a infância... com a nostalgia, porque a gente toca as músicas que passaram na tevê há 10 anos. É um gosto que a gente tem".

Para além dos gêneros, as entrevistas coletadas adensam a importância do universo sonoro-musical para que os animês ganhem força para permanência na memória, aqui em seu aspecto simbólico e também neurobiológico, e, como narrativa, permitam o deslocamento de seus personagens para serem selecionados e materializados no cosplay. $O$ cosplayer Lucas, 23 anos, confessa gostar de anime songs muito mais do que $J$ Pop ou $K$ Pop, porque "são músicas de episódios de animês que você acaba guardando, músicas legais, marcantes".

O grupo Iikagen parece concordar com Lucas. Em entrevista, Raoni responde como sente a reação do público a partir das músicas que tocam:

Uma palavra que resumo muito isso é a nostalgia, tem gente que canta junto que dá pra ver os olhinhos brilharem, animês e desenhos mexem muito com quem somos e com quem vamos ser, é a nossa infância na frente da telinha horas e horas imaginando ser o Goku ${ }^{10}$ ou $o$ Seya ${ }^{11} \mathrm{e}$

\footnotetext{
${ }^{10}$ Goku é o protagonista do mangá, posteriormente transformado em animê, Dragon Ball, criado por Akira Toryama, na década de 80.

${ }^{11}$ Seya é o cavaleiro de Pégasus, do mangá e animê Cavaleiros do Zodíaco, de Masami Kurumada. Este animê é um dos mais citados nas entrevistas realizadas durante os eventos descritos.
} 
imaginando várias aventuras, têm músicas que tocam o coração da galera (banda Iikagen, Raoni, por email). ${ }^{12}$

Fernando canta na plateia o refrão do animê Dragon Ball durante a apresentação da Iikagen, no Anime Party. Relata: "sou Fernando, tenho 21 anos, sou da Mooca, otaku, nerd com muito orgulho". Pergunto sobre seu entusiasmo, ao ouvir a música. O jovem otaku continua:

não tem como não se animar, ouvindo um animê que você gosta, [...] você cresce ouvindo isso, o Dragon Ball, por exemplo. A maioria das pessoas cresceu ouvindo, cresceu assistindo isso, é uma filosofia de vida. As pessoas falam: tem porrada. Tem porrada? Tem. Mas é uma lição que passa [...] a maioria dos animês passa amizade acima de tudo. Amizade, determinação. Tá impossível? É impossível? Mas eu vou conseguir.

A voz funciona como elemento musical. Contamina a língua. "A utilização musical de palavras e de frases com ênfase na modulação e na acentuação natural da fala realça o sentido das palavras e amplia sua utilização" (BANG, 1991: 28). Não ao acaso, Akira, 23 anos, cosplayer, fotógrafo e estudioso da cultura japonesa, ${ }^{13}$ reitera a importância da voz da personagem. Narra, então, sua experiência como espectador:

eu não consigo assistir em japonês porque a voz dos personagens já ficou tão marcada pra mim que você não identifica o personagem, você perde a ligação que você tinha com o personagem, com a história, porque quem está contando a história ali na verdade são os dubladores [..]. quem conta a história nas animações é a voz, é a dublagem. Se você tiver uma dublagem porca e mal feita, você vai perder todo o brilho da história, você pode ter o melhor filme do mundo, mas mal dublado vai ficar uma porcaria.

A voz significante impressiona a memória por suas qualidades, afinal, como explica Paul Zumthor (1997: 12),

\footnotetext{
${ }^{12}$ Entrevistei os membros da banda likagem no evento Anime Party. Posteriormente entrevistei o grupo por email. Ambas as entrevistas foram realizadas em abril de 2012. São Paulo.

${ }^{13}$ Rafael Akira Yoshioka Barros escreveu Yume no Tamashi: o espírito do sonho (2011), trabalho de conclusão de curso em Jornalismo que apresenta um panorama sobre as bandas nacionais cuja influência vem da cultura pop japonesa.
} 
não há dúvida de que a voz constitui no inconsciente humano uma forma arquetípica: imagem primordial e criadora, ao mesmo tempo energia e configuração de traços que predeterminam, ativam, estruturam em cada um de nós suas experiências primeiras, seus sentimentos, seus pensamentos.

Vale dizer, ainda, que os ouvidos e a percepção auditiva beneficiam-se da evolução do desenvolvimento humano, uma vez que as regiões auditivas já se encontram, na ocasião do nascimento, capazes de processar informações associadas aos sons do exterior e podem interpretá-los, distinguindo frequências de vozes, reagindo ao mundo, pois, "desde os primeiros anos de vida, os bebês são sensíveis a aspectos sonoros, como o tom e as diferenças de ritmo fundamentais para a música e que estão subjacentes no intenso interesse humano pela música que perpassa as culturas" (ROSE, 2006: 140).

As questões referentes à neurobiologia da audição ajudam a compreender a presença da voz, da música, dos sons, enfim, em variegadas experiências culturais, dos jogos da infância aos sucessos da sociedade do entretenimento, como demonstra o consumo musical na cena cosplay. Mas para que os imputs sonoros se transformem em percepção é preciso o auxílio da capacidade da memória. É ainda o neurocientista Steven Rose quem aponta a existência de períodos críticos para a formação das memórias e que este aprendizado inicial dará forma à percepção: "nossa juventude propicia os contornos dentro dos quais nossos mundos perceptivos são formados" (ROSE, 2006: 145). Não é abusivo afirmar o quanto as primeiras apreensões sonoras do espaço em que passamos os primeiros anos de nossas vidas são fundamentais para a sensibilização e significação destes espaços e tempos. A paisagem sonora da infância mediatizada pelos animes songs e outros bordões podem dar sentido à permanência destas canções em outras épocas, como nos festivais de cosplays.

Importa, ainda, ressaltar que os repertórios acionados na cena cosplay não significam memória apenas porque falam ao passado saudoso, mas também indicam o futuro, prenhe de avatares, herdeiros já descolados dos animês de sucesso dos anos 1980/1990. Mesmo assim, estes avatares carregam como meme, unidade de informação que se reproduz na cultura (NUNES, 2001), a voz, a tessitura sonora, ainda que sintetizadas. 
Ana Paula, 17 anos, veio de Jaú, interior do estado de São Paulo, para participar do Anime Dreams 2012. Começou a gostar de cultura japonesa, na infância, depois da morte da avó. Assistia aos animês na tevê e, agora, a internet é o meio escolhido para baixar os vídeos e outras criações que vão alçando o lugar simbólico e afetivo para a montagem do cosplay, a exemplo de Miku Hatsune, a personagem que ela encarna: uma vocaloide. Avatar de uma garota kawaii: longos cabelos azuis, roupas colegiais e, que, vez por outra, segura um alho-poró. É a primeira vocaloide da segunda geração.

Vocaloid é um software, idealizado pela Yamaha em meados de 2003, cuja função é cantar. Inicialmente, os vocaloides serviam de backvocals para artistas "reais", porém, seu sucesso gerou aprimoramentos. Assim, com base em um banco de vozes reais, o software favorece a formação de palavras e frases através de fonemas. Segundo o site Vocaloid Brasil ${ }^{14}$, há no mercado sete companhias produzindo voicebanks para o vocaloid. A segunda versão, Vocaloid 2, da qual Miku Hatsune faz parte, possui maior poder de sintetização da voz.

As performances das vocaloides são transmitidas via internet, por meio de vídeos que têm servido não só à divulgação da música, mas igualmente à expansão destes avatares, tal qual a personagem Miku, que, entre outras e outros volcaloides, ganharam o mercado de brinquedos, roupas, acessórios, e foi bastante comum encontrála como cosplay durante os eventos analisados aqui.

\section{Considerações em processo}

O consumo musical na cena cosplay, considerada uma semiosfera, estrutura-se como código cultural. Armazena informações de um mundo já vivido e, de outro modo, idealizado. Valendo-se da suscetibilidade humana ao universo dos sons, dos ouvidos que nunca se fecham, as paisagens sonoras produzidas por animês intensificam a condição estruturante das mídias nas culturas contemporâneas e seu poder de falar à memória, passado reconstruído ou futuro invencionado. Como código, o consumo musical analisado neste paper também processa informações. Transborda a dimensão do afeto, ainda que imiscuído aos desígnios ideológicos percebidos nas letras dos animês, voltadas à superação, à perseverança e à vitória, de algum modo, respondendo

\footnotetext{
${ }^{14}$ Disponível em< http://vocaloidbrasil.com $>$. Último acesso em 10 de abril de 2012.
} 
aos propósitos do empreendedor de si mesmo forjado no neoliberalismo dos anos de 1980. Todavia, os repertórios musicais consumidos operam vinculações entre os jovens, alimentam a paisagem sonora que assegura, por meio da repetição que ritualiza a infância já vivida, a permanência desta cena na cultura juvenil.

\section{Referências}

AMARAL, A. e DUARTE, R. A Subcultura cosplay no Orkut: comunicação e sociabilidade online e off-line. In: BORELLI, S. e FREIRE FILHO, J. Culturas Juvenis no Século XXI. São Paulo: Educ, 2008.

BANG, Claus. Um mundo de som e música. In: RUUD, Even (org.). Música e Saúde. São Paulo: Summus, 1991.

BARROS, Akira. Yume no Tamashi - o espírito do sonho. Trabalho de Conclusão de Curso (graduação) - apresentado ao Instituto de Ciências Sociais e Comunicação da Universidade Paulista, São Paulo, 2011.

BORELLI, Sílvia e FREIRE FILHO, João (orgs.). Culturas Juvenis no Século XXI. São Paulo: Educ, 2008.

BRAGA, José Eduardo. Músicas do mundo. Coimbra: Imprensa da Universidade de Coimbra, 2009.

COELHO Jr, L, e SILVA, Sara Santos. Cosplayers como fenômeno psicossocial: do reflexo da cultura de massa ao desejo de ser herói. Revista Brasileira de Desenvolvimento e Humano, 17(1): $2007.64-75, \quad$ Disponível em <http://www.revistasusp.sibi.usp.br/pdf/rbcdh/v17n1/06.pdf.> Último acesso em 25 de setembro de 2011.

FEATHERSTONE, Mike. Cultura de consumo e pós-modernismo. São Paulo: Nobel, 1995.

FERREIRA, V. Ondas, cenas e microculturas juvenis; In: Plural. Revista do Programa de Pós-Graduação do Progrma de Sociologia da USP. São Paulo, v.15, p. 99-128, 2008.

HERSCHMANN, Micael. Uso criativo dos videogames musicais na cena independente e potencial de crescimento dessas plataformas gerando dividendos para as majors. In: HERSCHMANN, M (org.). Nas bordas e fora do mainstream musical. São Paulo: Estação das Letras e Cores, 2011.

LOTMAN, Iuri. Acerca de la Semiosfera. In: La Semiosfera I. Madri: Ediciones Cátedra, 1996.

MACHADO, Irene. Escola de Semiótica. São Paulo: Ateliê Editorial, 2003.

NAGADO, Alexandre. O mangá no contexto da cultura pop japonesa e universal. In: LUYTEN, Sonia. Cultura Pop Japonesa. São Paulo: Hedra, 2005.

NUNES, Mônica. A Memória na Mídia: A Evolução dos Memes de Afeto. São Paulo: Annablume/FAPESP, 2001. 
ROCHA, Everardo e BARROS, Carla. Entre mundos distintos: notas sobre a comunicação e consumo em um grupo social. In: BACCEGA, Maria Aparecida (org.). Comunicação e culturas do consumo. São Paulo: Atlas, 2008.

ROCHA, Rose de Melo. Comunicação e Consumo: por uma leitura política dos modos de consumir. In: BACCEGA, Maria Aparecida(org.). Comunicação e culturas do consumo. São Paulo: Atlas, 2008.

ROSE, Steven. $O$ Cérebro no século XXI. São Paulo: Globo, 2006.

SCHAFER, Murray. A afinação do mundo. São Paulo: Editora da Universidade Estadual Paulista, 2001.

STRAW, Will. Cultural Scenes. Loisir et societé/society and leisure, vol.27, n.2., 2004.

ZUMTHOR, Paul. Introdução à Poesia Oral. São Paulo: Hucitec, 1997. 